\title{
Variable pattern of visual recovery of Leber's hereditary optic neuropathy
}

\author{
Makoto Nakamura, Misao Yamamoto
}

\begin{abstract}
Aims-To investigate pattern of visual recovery of nine patients with Leber's hereditary optic neuropathy (LHON) and a mitochondrial DNA mutation at $\mathbf{1 1 7 7 8 .}$ Methods-Recovery was judged significant when a gain of two lines or more in the Landolt ring chart, $10 \mathrm{~dB}$ or more improvement of the mean deviation of static perimetry, or improvement of critical flicker frequency (CFF) over $35 \mathrm{~Hz}$ was shown.

Results-All three visual functions tested dramatically recovered in one patient. Two other patients exhibited isolated improvement of CFF or visual field, respectively. Conclusion-Partial improvement of visual function may be more widespread than previously recognised in LHON patients with the 11778 mutation.

(Br F Ophthalmol 2000;84:534-535)
\end{abstract}

Leber's hereditary optic neuropathy (LHON) is an acute, bilateral optic atrophy mainly affecting young men. ${ }^{12}$ Three primary mutations of mitochondrial (mt) DNA are known to be associated with the maternal inheritance trait of LHON. ${ }^{12}$ Although visual prognosis is generally poor in patients with LHON, and especially an mt DNA mutation at nucleotide position 11778, spontaneous recovery is occasionally reported. ${ }^{34}$ In this study, we investigated frequency and pattern of visual recovery in LHON patients with the 11778 mutation.

Correspondence to: Dr Makoto Nakamura, H166, Departments of Ophthalmology and Cellular and Molecular Physiology, Penn State University College of Medicine, H166, 500 University Drive, Hershey, PA 17033, USA mxn15@psu.edu

Accepted for publication 14 January 2000

\section{Materials and methods}

Nine patients with LHON with the 11778 mutation were studied; they had been followed up for at least 1 year after the onset of disease. The study was performed according to the guidance of the Declaration of Helsinki and informed consent was obtained from all the patients. The molecular biology technique to

Table 1 Summary of patient data

\begin{tabular}{|c|c|c|c|c|c|c|c|c|}
\hline \multirow[b]{2}{*}{ Case } & \multirow[b]{2}{*}{ Sex } & \multirow{2}{*}{$\begin{array}{l}\text { Onset } \\
\text { (years) }\end{array}$} & \multirow{2}{*}{$\begin{array}{l}\text { Follow up } \\
\text { period (years) }\end{array}$} & \multicolumn{2}{|l|}{$\begin{array}{l}V A \\
R E / L E\end{array}$} & \multicolumn{2}{|c|}{$\begin{array}{l}C F F(H z) \\
R E / L E\end{array}$} & \multirow{2}{*}{$\begin{array}{l}\text { VF } \\
\text { improvement }\end{array}$} \\
\hline & & & & nadir & final & nadir & final & \\
\hline 1 & M & 15 & 4 & $0.1 / 0.1$ & $0.6 / 0.7$ & $21 / 21$ & $38 / 41$ & Yes \\
\hline 2 & $M$ & 17 & 6 & $0.01 / 0.01$ & $0.01 / 0.01$ & $23 / 24$ & $44 / 43$ & No \\
\hline 3 & $M$ & 26 & 4 & $\mathrm{HM} / 0.01$ & $0.01 / 0.01$ & $13 / 20$ & $19 / 22$ & Yes \\
\hline 4 & $\mathrm{~F}$ & 48 & 4 & $0.02 / 0.02$ & $0.04 / 0.04$ & $22 / 21$ & $24 / 20$ & No \\
\hline 5 & M & 13 & 6 & $0.05 / 0.02$ & $0.05 / 0.07$ & $10 / 15$ & $18 / 12$ & No \\
\hline 6 & $M$ & 15 & 4 & $0.05 / 0.03$ & $0.05 / 0.04$ & $19 / 18$ & $17 / 16$ & No \\
\hline 7 & $M$ & 23 & 5 & $0.01 / 0.01$ & $0.02 / 0.01$ & $16 / 21$ & $20 / 18$ & No \\
\hline 8 & $M$ & 49 & 7 & $0.01 / 0.01$ & $0.01 / 0.01$ & $21 / 20$ & $18 / 19$ & No \\
\hline 9 & $M$ & 51 & 1 & $0.01 / 0.01$ & $0.01 / 0.01$ & $19 / 18$ & $24 / 22$ & No \\
\hline
\end{tabular}

$\mathrm{VA}=$ visual acuity, $\mathrm{CFF}=$ critical flicker frequency, $\mathrm{VF}=$ visual field, $\mathrm{HM}=$ hand movement. confirm the 11778 mutation has been described previously. ${ }^{5}$

Corrected visual acuity, mean deviation of static perimetry, and critical flicker frequency (CFF) were periodically tested using the Landolt ring visual chart, the C30-2 program on the Humphrey field analyser (Model 750) under fixation monitoring, and handy flicker (Neitz), respectively.

Significant improvement of visual acuity was defined as a gain of the two lines or more from nadir. Improvement of the visual field was judged significant when the mean deviation in the last three consecutive tests was better than $10 \mathrm{~dB}$ compared with the average of three tests at the nadir.

CFF was measured in a relatively dark room according to the method of Woung et al. ${ }^{6}$ In brief, the flicker rate of a red target stimulus at a viewing distance of $25 \mathrm{~cm}$ was gradually increased until an examinee perceived the stimulation as a constant illumination. Then the rate was decreased until the examinee recognised flickering; this rate was recorded. Among three sets of this procedure, the lowest rate was adopted as a CFF of the subject at the specific day. Our preliminary study indicated that the average of CFF in a total of 50 normal adults was 36.2 (SD 2.3) Hz, whereas CFF in 26 age matched patients who had visual acuity and field similar to the current cases and optic neuritis or traumatic, ischaemic, or compressive optic neuropathy was $25 \mathrm{~Hz}$ or below (data not shown). These values are consistent with those of other investigators. ${ }^{6}{ }^{7}$ Improvement was judged significant if CFF exceeded $35 \mathrm{~Hz}$ at recovery.

\section{Results and discussion}

The patients' data are summarised in Table 1 .

All but one patient (case 4) showed reliable perimetric results with probability indices for false negative and positive responses and fixation loss being $15 \%$ or less.

Three out of the nine patients showed significant improvement of at least one of the three visual functions tested.

Case 1 exhibited a dramatic recovery of visual acuity from 0.1 in both eyes to 0.6 in the right eye and 0.7 in the left. Central scotoma completely disappeared (Fig 1; upper panel) and CFF fully recovered.

Case 2 demonstrated a remarkable improvement of CFF from $23 \mathrm{~Hz}$ right eye and $24 \mathrm{~Hz}$ left eye at the nadir to $43 \mathrm{~Hz}$ both eyes a year after the second eye was involved. He did not significantly recover his visual acuity or field.

Case 3 exhibited a significant improvement of the mean deviation from -27 to $-15 \mathrm{~dB}$ right eye and from -28 to $-17 \mathrm{~dB}$ left eye 

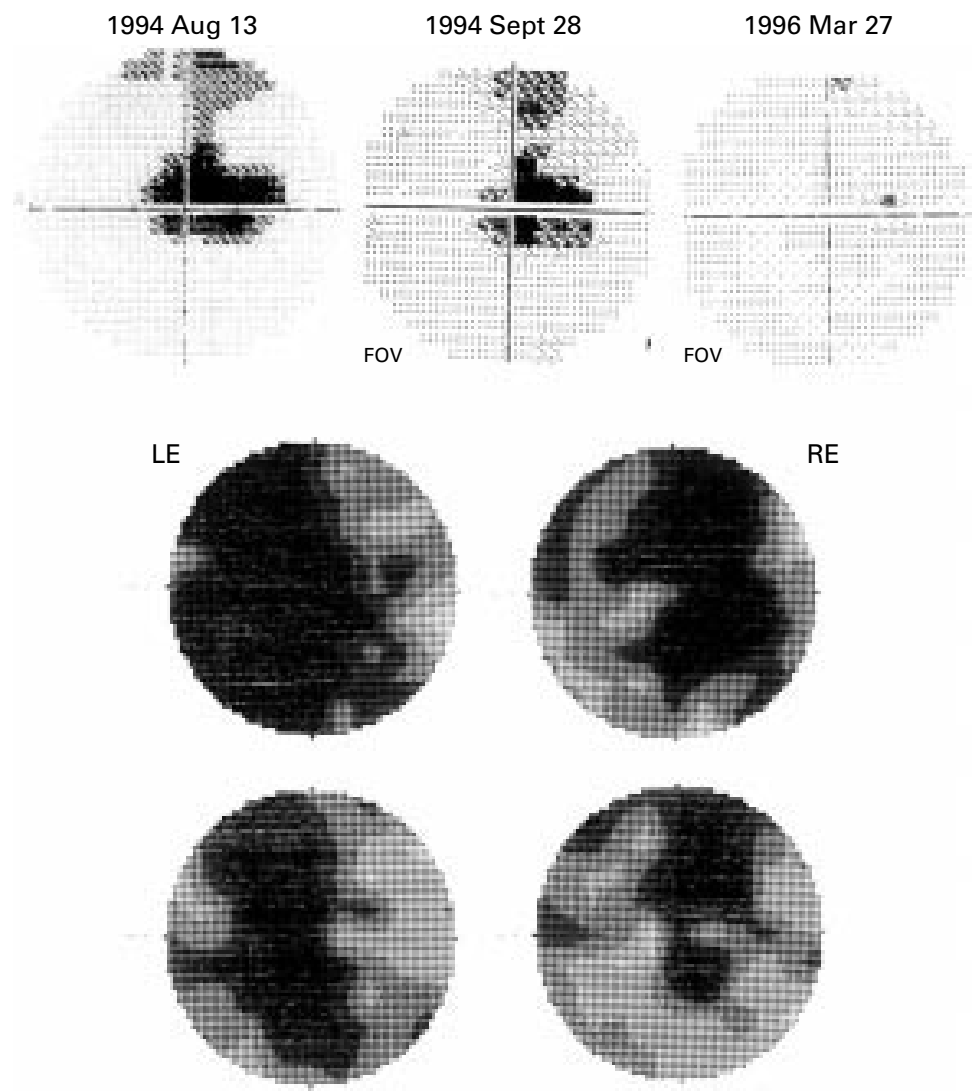

Figure 1 Upper panel; complete resolution of central scotoma in the right eye of case 1. Middle panel; central scotoma at nadir in case 3. Lower panel; amelioration of the visual field defect in case 3.

(Fig 1; middle and lower panels). Visual acuity and CFF remained unchanged.

These three patients had no systemic diseases and no tobacco and alcohol misuse, whereas among the remaining seven patients without recovery, case 4 had diabetes mellitus and systemic hypertension and cases 8 and 9 were tobacco and alcohol misusers. These support previous observations that metabolic compromise is likely to precipitate expression of LHON. ${ }^{8}$

The current data did not corroborate the previous reports suggesting that patients with the onset at 15 years or younger tended to show better visual outcomes. ${ }^{34}$

Although cases $1-5$ had been given idebenone $30 \mathrm{mg}$ daily $^{9}$ and vitamin B2 $40 \mathrm{mg}$ throughout the follow up period, the small sample size and no randomisation precluded us from drawing a rigorous conclusion regarding their effectiveness.
Taken into account the poor prognosis of LHON patients with the 11778 mutation, the above visual recovery rate $(=3 / 9)$ seems noteworthy. Some patients with LHON are known to recover vision by developing small islands of normal vision within their central scotoma. ${ }^{3}$ Unless the fenestrated scotoma unmasks the most central area, the decreased visual acuity remains unchanged. This indicates that the recovery rate is likely to be underestimated when one solely considers visual acuity.

Since two current patients, whose central scotoma was substantially reduced, showed relatively mild visual field defect even at the nadir, the size of the central scotoma at the nadir may be one of the critical factors determining to what extent visual function is improved.

CFF is suggested to be a more sensitive detector for subtle optic nerve dysfunction than visual acuity. ${ }^{6}{ }^{10}$ It is affected earlier and recovers later than visual acuity in patients with various kinds of optic neuropathy. The dominant and isolated recovery of CFF observed in cases 1 and 2, respectively, is very peculiar. Since CFF is presumed to reflect the magnocellular function, ${ }^{10}$ the above results may suggest that the magnocellular function is preferentially rescued, at least in some patients with LHON.

This study was presented in part at 12th International Neuro-ophthalmology Symposium, Dublin, Ireland, 19-22 July 1998. This study was supported in part by grant in aid for scientific research 09771427 from the Ministry of Education, Science, Sports, and Culture of Japan (MN).

1 Wallace DC, Singh G, Lott MT, et al. Mitochondrial DNA mutation associated with Leber's hereditary optic neumutation associated with Leber's

2 Chalmers RM, Schapira AHV. Clinical, biochemical and Chalmers RM, Schapira AHV. Clinical, biochemical and
molecular genetic features of Leber's hereditary optic neuropathy. Biochim Biophys Acta Bienergetics 1999;1410:14758

3 Stone EM, Newman NJ, Miller NR, et al. Visual recovery in patients with Leber's hereditary optic neuropathy and the 11778 mutation. F Clin Neuro-ophthalmol 1992;12:10-14.

4 Nikoskelainen EK, Huoponen K, Juvonen V, et al. Ophthalmologic findings in Leber's hereditary optic neuropathy, with special reference to mt DNA mutations. Ophthalmology 1996;103:504-14.

5 Nakamura M, Fujiwara Y, Yamamoto M. Homoplasmic and exclusive ND4 gene mutation in Japanese pedigrees with
Leber's disease. Invest Ophthalmol Vis Sci 1993;34:488-95.

6 Woung L-C, Wakakura M, Ishikawa S. Critical flicker frequency in acute and recovered optic neuritis. $\mathscr{f} p n \mathcal{f} O p h$ thalmol 1993;37:122-9.

7 Jacobson DM, Olson K. Impaired critical flicker frequency in recovered optic neuritis. Ann Neurol 1991;30:213-15.

8 Kerrison JB, Newman NJ. Clinical spectrum of Leber's Kerrison JB, Newman NJ. Clinical spectrum of Leber's
hereditary optic neuropathy. Clin Neurosci 1997;4:295301 .

9 Mashima Y, Hiida Y, Oguchi Y. Remission of Leber's hereditary optic neuropathy with idebenone. Lancet 1992; 340:368-9.

10 Otori T. Basic and clinical aspects of modern perimetry. Nippon Ganka Gakkai Zasshi 1998;102:779-95 